\title{
Review
}

\section{Genetic Modifiers for Neuromuscular Diseases}

\author{
Kay-Marie Lamar and Elizabeth M. McNally* \\ Department of Human Genetics, Department of Medicine, Section of Cardiology, The University of Chicago, \\ Chicago, IL, USA
}

\begin{abstract}
Neuromuscular diseases, which encompass disorders that affect muscle and its innervation, are highly heritable. Genetic diagnosis now frequently pinpoints the primary mutation responsible for a given neuromuscular disease. However, the results from genetic testing indicate that neuromuscular disease phenotypes may vary widely, even in individuals with the same primary disease-causing mutation. Clinical variability arises from both genetic and environmental factors. Genetic modifiers can now be identified using candidate gene as well as genomic approaches. The presence of genetic modifiers for neuromuscular disease helps define the clinical outcome and also highlights pathways of potential therapeutic utility. Herein, we will focus on single gene neuromuscular disorders, including muscular dystrophy, spinal muscular atrophy, and amyotrophic lateral sclerosis, and the methods that have been used to identify modifier genes. Animal models have been an invaluable resource for modifier gene discovery and subsequent mechanistic studies. Some modifiers, identified using animal models, have successfully translated to the human counterpart. Furthermore, in a few instances, modifier gene discovery has repetitively uncovered the same pathway, such as TGF $\beta$ signaling in muscular dystrophy, further emphasizing the relevance of that pathway. Knowledge of genetic factors that influence disease can have direct clinical applications for prognosis and predicted outcome.
\end{abstract}

Keywords: Genetic modifier, muscular dystrophy, amyotrophic lateral sclerosis, spinal muscular atrophy

Abbreviations: Amyotrophic lateral sclerosis (ALS), Duchenne Muscular Dystrophy (DMD), Emery Dreifuss Muscular Dystrophy (EDMD), Ephrin type A receptor 4 (EPHA4), genomewide association study (GWAS), induced pluripotent stem cell (IPSC), Latent TGF $\beta$ binding protein (LTBP), limb girdle muscular dystrophy (LGMD), plastin 3 (PLS3), transforming growth factor $\beta$ (TGF $\beta$ )), transforming growth factor $\beta$ receptor II (TGFBR2), Spinal Muscular Atrophy (SMA), secreted phosphoprotein 1 (SPP1), Survival of Motor Neuron (SMN), quantitative trait locus (QTL), Zinc finger protein 1 (ZPR1)

\section{INTRODUCTION}

Genetic interactions were long hypothesized to be relevant for neuromuscular diseases (NMDs). With improvement in sequencing technology, the primary genetic mutation responsible for many monogenetic NMDs, especially the muscular dystrophies, is commonly determined. With knowledge of the primary

*Correspondence to: Elizabeth McNally, MD, PhD, University of Chicago, Dept Medicine, Section of Cardiology, 5841S. Maryland MC6088, Chicago, IL 60637, USA. Tel.: +1 773702 2672; Fax: +1 773702 2681; E-mail: emcnally@uchicago.edu. gene defect, it is now apparent that the range of clinical presentation associated with mutation in a single gene is often broader than previously anticipated. Correspondingly, research efforts are now directed at unearthing genes that modify the effect of a primary disease causing mutation. Most monogenic diseases have phenotypes that vary widely, even in individuals with the same disease-causing mutation. This indicates the presence of additional factors, such as modifier genes, that alter disease outcome. Below we will discuss the current approaches used to discover modifier genes, different types of modifier genes that have been identified for NMDs, and the importance of modifier 
genes in revealing pathways involved in NMD pathogenesis.

\section{Modifier genes}

A modifier gene is a genetic locus that enhances or suppresses the outcome of the primary disease causing mutation. Modifier genes may affect different aspects of disease, such as age at onset, severity of disease, or duration of disease, and may act on some disease parameters but not others. For example, a modifier may regulate disease onset, but have no effect on disease duration. Genetic modifiers may act only on a specific subtype of NMD, while others may act on many NMDs. For example, the EPHA4 and SMN2 genes are modifiers of both amyotrophic lateral sclerosis (ALS) and spinal muscular atrophy (SMA) [1-4]. PGC1 $\alpha$ has been found to modify ALS, Huntington's disease and Parkinson's disease $[5,6]$. These findings emphasize the importance of collating findings across different NMDs, since pathways that modify more than one type of disease become excellent targets for therapy development.

\section{Neuromuscular diseases and the significance of genetic modifiers}

Inherited NMDs affect an estimated 1:3000 people worldwide, causing muscle weakness, chronic disability and even premature death [7]. NMDs create a significant financial burden, both on patients and families and the healthcare system; the total US cost of NMDs is estimated to be over $\$ 1$ billion per year [8]. NMDs encompass the muscular dystrophies, motor neuron diseases, neuromuscular junction diseases, and others. Despite a good understanding of the primary genetic basis of many NMDs, there are few, if any, curative therapies. Considerable progress is being made in the areas of gene correction/restoration, cell based therapies, and supportive care, so that quality and quantity of life is improving with NMD. Despite progress, new approaches are needed, and determining the pathways that can alter the course of disease may reveal biological pathways useful for prognosis and therapy development.

Uncovering modifier genes can also have direct clinical application. For example, genetic markers that indicate an increased potential for cardiorespiratory complications can be used to institute earlier supportive therapy. Awareness of modifier genes can also be helpful when designing clinical trials. Clinical trials in rare diseases are complicated by having to recruit sufficient numbers of subjects. Identifying those subjects who are outliers can help stratify findings with strong scientific rationale. The ability to design a study equipped with the knowledge of disease modifying factors would make a clinical trial more efficient; one could stratify patients based on genotype at a modifier locus or use modifier loci as covariates in the analysis [9]. Reducing phenotypic variation permits smaller sample sizes that are more cost-effective, and also encourages the study of rare diseases where large sample sizes are often infeasible.

\section{APPROACHES FOR DISCOVERING MODIFIER GENES}

The two major approaches for identifying genetic modifiers rely on examining candidate genes, based on biological knowledge of a gene or pathway, or unbiased approaches, which rely on genomewide scans or gene profiling. Most often, the search for modifiers relies on a blend of these methods. Candidate gene approaches can be augmented by gene expression profiling or other means, which can link a pathway to a given disease process. Limiting the number of genes to be tested avoids the burden of multiple testing, and the candidate gene approach has been successful in identifying many modifier genes including chondrolectin for SMA, CNTF for ALS, and osteopontin for Duchenne Muscular Dystrophy (DMD) [10-12].

Genomewide approaches to identify modifiers may employ quantitative trait locus (QTL) mapping or genomewide association studies (GWAS) to find statistical associations between genetic determinants across the genome and quantitative phenotypes, such as measurements of disease severity. GWAS necessitates a large sample size for sufficient power, and choosing the correct phenotypes for study requires a sound understanding of the disease process, the targeted cell or tissue type, as well as reproducible and reliable measures. There are some disadvantages to GWAS, such as the large sample size required and the high burden of multiple testing. Furthermore, ascribing the modifier effect to a gene within a GWAS locus is often biased toward genes that are already known to have a biological role related to the underlying disease. Genomewide approaches also entail whole exome, genome, transcriptome, and methylome analyses. These approaches have less bias, and thus the capacity to reveal surprising new pathways. For example, $P L S 3$, a modifier of SMA in worms, flies, zebrafish, mice, and humans, was originally discovered by a transcriptome-wide differential 
expression analysis on a few individuals with highly discordant phenotypes [13-15].

Mapping modifiers in human NMD populations can be achieved using cohorts of related or unrelated individuals. The mapping cohort can be a large group of unrelated individuals who carry a primary mutation in the same gene. In this case, the primary gene mutations are likely to vary and analysis needs to account for heterogeneity that arises from having different primary gene mutations. An alternative approach relies on disease segregation in large families, where the genetic background may be less diverse and, importantly, individuals share the same primary gene mutation. For example, this technique was utilized in a study of the largest known Emery-Dreifuss muscular dystrophy (EDMD) family, consisting of 59 family members segregating an autosomal dominant form of EDMD due to a mutation in $L M N A$ [16]. A strong linkage signal on chromosome 2 was associated with earlier disease onset, and this region includes the DES gene encoding desmin, an intermediate filament protein like $L M N A$ [16].

Modifier gene discovery thus far mainly focused on identifying variants that affect the expression or sequence of genes that encode proteins. However noncoding RNAs, such as micro RNAs (miRNAs) and small nucleolar RNAs (snoRNAs), have been shown to play a role in human disease and are poised to act as modifiers as well [17]. miRNAs have been shown to play an important role in skeletal muscle homeostasis and function [18], and identifying variants that affect binding of these miRNAs could lead to novel therapeutic options for NMDs.

\section{Animal models for mapping genetic modifiers}

Animal models of NMD offer some advantages for QTL mapping. Using animal models for mapping reduces variability arising from nongenetic causes, especially those that derive from environmental differences. Since the environment can be better controlled for in animal models, as opposed to humans, the degree of phenotypic variability attributed to diet or other factors can be minimized. Additionally, population size is less problematic since sufficiently large mapping cohorts can be more easily developed using animal models. Like GWAS, the success or failure of QTL mapping is highly dependent on using reliable and representative measures of disease severity. The major disadvantage of using animal models is the modifier pathway may not translate to the human condition.
Genomewide RNAi screening has also been used to identify modifier genes of NMDs. For example, Dimitriadi et al. used a high-throughput RNAi screen for modifiers of SMA in C. elegans [14]. From this approach, four genes were identified that exacerbated $S M N$ loss-of-function defects. Using functional conservation as a secondary screen, two of these four genes exerted a similar effect in a Drosophila model [14]. Conversely, an RNAi screen in C. elegans was used to evaluate 40 previously identified candidate modifier genes from a Drosophila SMA model [13]. This screen identified 12 genes that modified SMA models in a cross-species manner. This approach was also used to validate $P L S 3$, initially identified as a modifier of human SMA, as a modifier of SMA in worms and flies.

For the muscular dystrophies, a genetic interaction screen in Drosophila was used to identify components that interact with the dystrogylcan-dystrophin complex [19]. Like model organisms, cell-based approaches can also be used to map modifiers. For example, Li et al. relied on a high throughput cell based screening approach used to identify modifiers of SMA [20]. An inducible model, where Smn was knocked down, produced a cell growth phenotype, which was ameliorated by both genetic and pharmacological factors. With increasing development of cell models for disease through IPSCs, this approach is likely to grow in the coming years.

\section{MODIFIERS OF MUSCULAR DYSTROPHY}

Osteopontin. Osteopontin, or secreted phosphoprotein 1 (SPP1) was identified as a modifier of DMD based on transcriptomic profiling [12]. SPP1 is upregulated in dystrophin deficient DMD patients and the $m d x$ mouse model $[21,22]$. SPP1 was found to be downregulated approximately 3 fold in mild patients versus severe DMD, indicating that downregulation of SPP1 may be protective in disease [12]. A single nucleotide variant referred to as $-66 \mathrm{~T}>\mathrm{G}$ (and also known as rs28357094) in the promoter of SPP1 correlated with disease severity in two cohorts of human DMD patients. Disease severity was measured by age at loss of ambulation in the test cohort, and then verified in a validation cohort using grip strength as the measure. The rare G allele of SNP rs28357094 was associated with more severe disease [12]. The $\mathrm{G}$ allele has previously been shown to decrease promoter strength in luciferase gene reporter assays [23], which would seemingly contradict downregulation of 
A

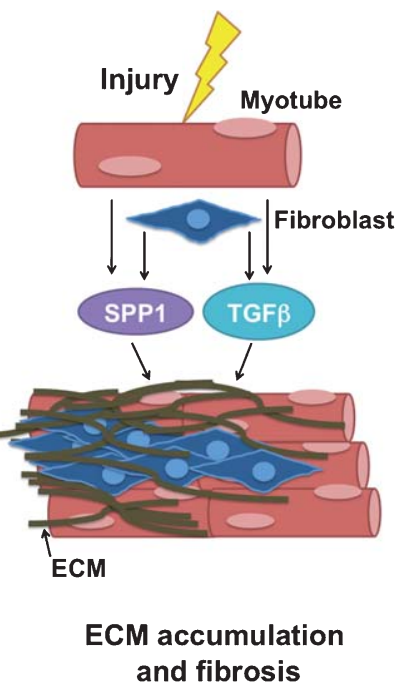

B

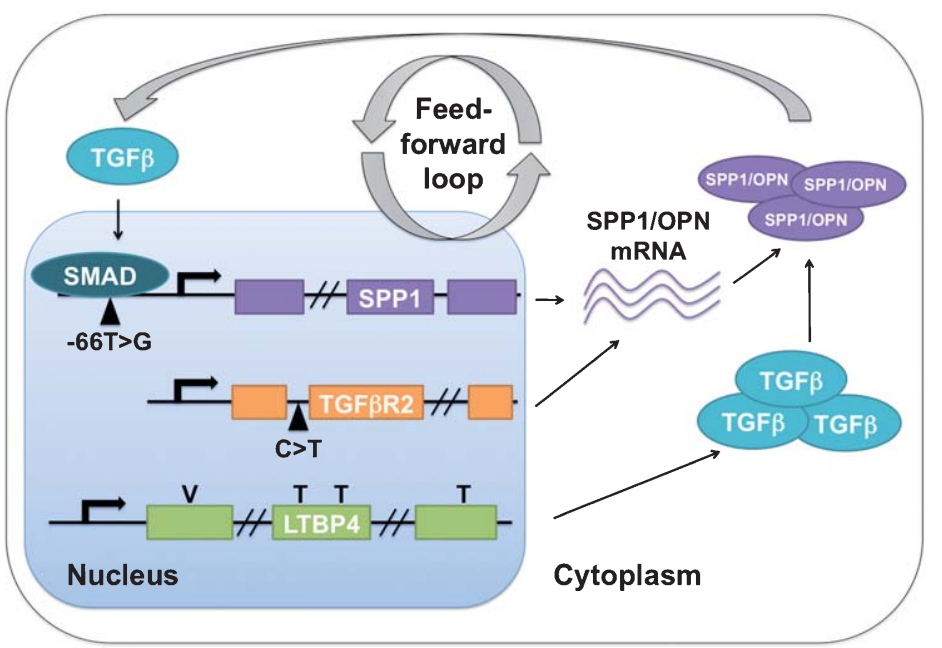

Fig. 1. The TGF $\beta$ pathway in muscular dystrophy. SPP1, encoding osteopontin (OPN), and TGF $\beta$ are co-regulated. A) When myofibers are injured, osteopontin and TGF $\beta$ signaling pathways are activated, leading to ECM accumulation and fibrosis of the muscle. B) TGF $\beta$ activates the SPP1 promoter through SMAD signaling. A SNP in the SPP1 promoter is associated with a more severe form of DMD. A SNP in TGFBR2 results in increased SPP1 expression. The "VTTT" allele of $L T B P 4$ leads to increased TGF $\beta$ signaling and is associated with a more severe form of DMD. Treatment of myoblasts with TGF $\beta$ results in increased osteopontin expression. The $m d x$ mouse deficient for $S P P 1 /$ osteopontin has reduced TGF $\beta$ signaling and reduced fibrosis.

$S P P 1$ being protective. However, the $S P P 1$ "G" allele may influence expression in a cell-type specific manner and/or be under the influence of steroids or hormones to account for its effect. Another study found no association between the same $\mathrm{G}$ allele in the SPPI promoter and SPP1 mRNA or protein expression in DMD patients, although the sample size was small [24]. One possibility for these conflicting studies is complex transcriptional regulation at this locus. The SPP1 gene is known to be regulated by sex hormones, which may also influence disease [25]. It is also possible that another variant in the region of rs28357094 mediates the DMD disease modifying effect, as this region has strong linkage disequilibrium. Pegoraro et al. also identified two other genes, ACTN3 and CELSR2, as modifiers of DMD. However when corrected for multiple testing, these genes were not significantly associated with disease severity in the replication cohort [12].

Genetic variation in SPPI has been implicated in a wide-variety of other diseases, including asthma, type 1 diabetes, rheumatoid arthritis, lupus, pseudoxanthoma elasticum (PXE), and multiple sclerosis (MS) [26-31]. $S P P 1$ is a phosphorylated acidic glycoprotein with multiple functions, including bone-remodeling, cell-mediated immunity, and wound healing. In skeletal muscle, myoblasts are an important source of osteopontin when tissue integrity is compromised [32]. Osteopontin is expressed at low levels in normal mouse muscle, but is highly upregulated following damage and is associated with areas of regeneration in $m d x$ mice $[32,33]$. These data implicate osteopontin as an important modulator of matrix remodeling post-injury. Transforming growth factor $\beta$ (TGF $\beta$ ) is also critical to tissue injury and remodeling, and the $S P P 1 /$ osteopontin and TGF $\beta$ pathways intersect. TGF $\beta$ binds and activates the SPP1 promoter [34]. Treatment of myoblast cultures with TGF $\beta 1$ results in increased osteopontin expression [32]. $m d x$ mice deficient in $S P P 1$ show a decrease in TGF $\beta 1$, which results in decreased fibrosis and increased muscle strength [21]. These results support a model where osteopontin expression leads to TGF $\beta$ activation and a feed forward mechanism where TGF $\beta$ also promotes osteopontin expression (Fig. 1). Interestingly, a SNP in TGFBR2, encoding the TGF $\beta$ receptor II protein, acts as a predictor of SPP 1 mRNA levels in DMD, further establishing the interdependence of $S P P 1$ and TGF $\beta$ [24]. There is evidence that $S P P 1$ acts in a sex-specific manner, which should be kept in mind when designing studies involving both males and females. In healthy controls, the $-66 \mathrm{~T}>\mathrm{G}$ variant of SPP1 is strongly associated with increased muscle volume in females, with individuals carrying the $\mathrm{G}$ allele showing $14-17 \%$ larger 
muscles [33]. In mice, Opn-null females had smaller muscles for five out of seven muscle groups examined, whereas males only displayed smaller muscle size for two of the muscle groups [33]. Genetic association studies of SPP1 in other diseases have also shown sex-specific effects [30, 35]. The SPPI promoter is estrogen responsive [25], which may explain some of these sex-specific effects.

Latent TGF $\beta$ binding protein 4 (LTBP4). Ltbp4 was originally found in a genomewide screen for modifiers of muscular dystrophy using a mouse model of limb girdle muscular dystrophy (LGMD) [36]. Mice lacking the dystrophin associated protein $\gamma$-sarcoglycan $(S g c g)$ share a similar disease course as $m d x$ mice. Sgcg mice in the DBA 2J strain have a more severe form of muscular dystrophy than $\mathrm{Sgcg}$ mice from the $129 \mathrm{SV} / \mathrm{J}$ strain or C57B16/J backgrounds [37]. Interbreeding these two strains produces a more diverse phenotypic range, which is quantified by measuring Evans Blue dye within muscle. Evans blue dye gains entry into myofibers when the sarcolemma has been disrupted, as occurs more easily with dystrophin or sarcoglycan mutations [38]. Hydroxyproline content was also used a quantitative measure of fibrosis since this modified amino acid is found in collagen. Mice with a short in-frame deletion altering a proline rich hinge region of LTBP4 protein have increased membrane leak and fibrosis compared to mice carrying an insertion at this locus [36].

To test whether LTBP4 modifies human muscular dystrophy, Flanigan et al. genotyped nsSNPs in LTBP4 in DMD patients and correlated the genotypes at these SNPs with age at ambulatory loss [39]. The four nsSNPs in the human LTBP4 gene are distributed along the length of the protein, although one falls near the region implicated in binding TGF $\beta$. Furthermore, the four nsSNPs are in linkage disequilibrium forming the "VTTT" or "IAAM" haplotypes, so named for the amino acid missense changes. DMD patients homozygous for the IAAM haplotype ambulated significantly longer than patients carrying LTBP4 SNPs constituting the VTTT haplotype [39]. The protective IAAM allele along with a history of steroid treatment had the largest advantage, having walked until age $12.5 \pm 3.3$ years. In comparison, ambulatory loss occurred at age $10.7 \pm 2.1$ years for those with the VTTT allele and steroid use. LTBP4 is an extracellular matrix protein that binds and sequesters TGF $\beta$ in the extracellular matrix and regulates its availability to the TGF $\beta$ receptor. Fibroblasts from humans carrying the risk allele of LTPB4 (VTTT) have increased TGF $\beta$ signaling compared to individuals carrying the protective allele (IAAM) [39].

TGF $\beta$ expression is increased in human DMD muscle and in the $m d x$ mouse [40, 41]. Increased TGF $\beta$ expression is associated with excessive matrix accumulation in a wide-variety of diseases, such as liver cirrhosis and cardiac fibrosis [42]. LTBP4 SNPs from the VTTT haplotype, or SNPs in linkage disequilibrium with these, have been associated with deleterious phenotypes in other diseases, such as functional impairment in chronic obstructive pulmonary disease, more aggressive tumors in colorectal cancer, and the expansion of abdominal aortic aneurysm [43-45]. The fact that both LTBP4 and SPP1 modify multiple diseases suggests that these genes have broad effects and may modify other NMDs.

Replication of genetic modifiers of disease in independent cohorts can be helpful, but especially challenging when working with rare diseases. For example, the SPP1 SNP association in DMD was replicated in two cohorts by Pegoraro et al. but was not replicated in the cohort studied by Flanigan et al. [39]. However, the absence of replication may relate to altered population structure, small samples sizes, and the necessity of correcting for multiple testing.

Annexin A6. Anxa6, encoding the membrane associated annexin A6 protein, was identified recently using the same strategy that discovered Ltbp4. A similar intercross strategy, coupled with genomewide mapping, was applied to the $S g c g$ mouse model of LGMD [46]. QTL mapping revealed a locus on chromosome 11 that was associated with two traits, membrane damage in muscle and increased heart mass in mice with muscular dystrophy. Further assessment of the chromosome 11 locus, using RNA sequencing and whole genome analysis of the DBA $2 \mathrm{~J}$ versus $129 \mathrm{SV} / \mathrm{J}$ strains of mice, pointed to Anxa6 as a modifier of muscular dystrophy. Annexin A6 is a phospholipid binding protein and is the most abundant annexin in the heart [47]. Annexins have been implicated in a number of cellular processes including membrane repair. Annexin A1 and A2 interact with dysferlin, a protein responsible for LGMD 2B, another subtype of recessive muscular dystrophy [48]. Overexpression of annexin A1 and annexin A2 is associated with increased disease severity in dysferlinopathies [49]. Annexin A2 and A6 act as scaffolding proteins and become part of lipid rafts within plasma membranes in both smooth muscle and skeletal muscle $[50,51]$. In an injury model in zebrafish, annexin A6 localized rapidly to the site of sarcolemmal disruption [52]. Using high resolution 
Table 1

Cross-species modifiers of Spinal Muscular Atrophy

\begin{tabular}{|c|c|c|c|c|c|c|}
\hline $\begin{array}{l}\text { Human } \\
\text { Gene } \\
\end{array}$ & $\begin{array}{c}\mathrm{Ce} \\
\text { gene }\end{array}$ & $\begin{array}{c}D m \\
\text { Gene }\end{array}$ & $\begin{array}{l}\text { Modifies } \\
\text { Ce SMA }\end{array}$ & $\begin{array}{l}\text { Modifies } \\
\text { Dm SMA }\end{array}$ & $\begin{array}{c}\text { Modifies } \\
\text { Human SMA }\end{array}$ & Function \\
\hline$P L S 3$ & plst-1 & Fim & $\mathrm{x}$ & $\mathrm{x}$ & $\mathrm{x}$ & $\begin{array}{l}\text { Formation and stabilization of F-actin } \\
\text { bundles }\end{array}$ \\
\hline$N C B P 2 L$ & $n c b p-2$ & Cbp20 & $\mathrm{x}$ & $\mathrm{x}$ & & $\begin{array}{l}\text { Nuclear export of mRNA, U snRNA } \\
\text { transport, nonsense mediated decay, } \\
\text { miRNA maturation }\end{array}$ \\
\hline$N P V F$ & $f l p-4$ & Fmrf & $\mathrm{x}$ & $\mathrm{x}$ & & $\begin{array}{l}\text { Activation of neuropeptide gated chloride } \\
\text { channels and G-protein coupled receptors }\end{array}$ \\
\hline USO1 & uso-1 & p115 & $\mathrm{x}$ & $\mathrm{x}$ & & $\begin{array}{l}\text { Vesicle tethering during trans-Golgi } \\
\text { transport }\end{array}$ \\
\hline PPARG & $n h r-85$ & Eip75B & $\mathrm{x}$ & $\mathrm{x}$ & & $\begin{array}{l}\text { Nuclear hormone receptor, regulation of } \\
\text { circadian rhythms }\end{array}$ \\
\hline FGFR3 & egl-15 & Btl & $\mathrm{x}$ & $\mathrm{x}$ & & $\begin{array}{l}\text { FGF signaling, NMJ function and } \\
\text { development }\end{array}$ \\
\hline ATF6 & atf-6 & CG3136 & $\mathrm{x}$ & $\mathrm{x}$ & & Unfolded protein stress response \\
\hline$P P P 1 R 13$ & ape-1 & CG18375 & $\mathrm{x}$ & $\mathrm{x}$ & & Prevention of inappropriate apoptosis \\
\hline NEK2 & nekl-3 & Nek2 & $\mathrm{x}$ & $\mathrm{x}$ & & Mitotic regulation \\
\hline$A C T N$ & atn-1 & actinin & $\mathrm{x}$ & $\mathrm{x}$ & & Actin-bundling \\
\hline STRN & cash-1 & CKA & $\mathrm{x}$ & $\mathrm{x}$ & & Calveolin and calmodulin-binding \\
\hline DYNLL2 & $d l c-1$ & ctp & $\mathrm{x}$ & $\mathrm{x}$ & & $\begin{array}{l}\text { Intracellular trafficking, regulation of } \\
\text { dynamin, F-actin assembly, transport of } \\
\text { TGF } \beta\end{array}$ \\
\hline$R N F 149$ & kcnl-2 & SK & $\mathrm{x}$ & $\mathrm{x}$ & & Potassium channel subunit \\
\hline$B M P R 2$ & $d a f-4$ & Wit & $\mathrm{x}$ & $\mathrm{x}$ & & TGF $\beta$ receptor subunit, cell specification \\
\hline$R X R A$ & $n h r-25$ & Usp & $\mathrm{x}$ & $\mathrm{x}$ & & $\begin{array}{l}\text { Ecdysone regulated molting, activation of } \\
\text { Smad } 2 \text { in muscles }\end{array}$ \\
\hline
\end{tabular}

SMA: Spinal muscular atrophy. Dm: Drosophila melanogaster. Ce: Caenorhabditis elegans.

stimulated emission depletion microscopy studies in mammalian muscle, annexin A6 was shown to form a discreet protective cap over the site of muscle disruption [46].

Genetic variation in Anxa6 from the DBA 2J strain focused on two SNPs in exons 11 and 15 that produced low-level amounts of an Anxa6 splice variant. This splice variant encodes a truncated annexin A6 protein, which interfered with the normal translocation of annexin A6 to the site of sarcolemmal disruption [46]. Truncated annexin A6 protein acted in a dominant negative manner and was associated with a more severe form of muscular dystrophy. It remains to be seen if ANXA6 modifies human muscular dystrophy, but the identification of this pathway highlights other genes and proteins that may alter muscle membrane repair. Moreover, whether Anxa6 modifies other mouse models of muscular dystrophy has not yet been shown.

\section{MODIFIERS OF SMA}

SMA is a progressive degenerative disorder affecting both lower and upper motor neurons. Loss and damage of motor neurons cause muscle weakness, atrophy, and eventual paralysis in SMA patients.
Ninety-five percent of SMA cases are caused by homozygous deletion of the SMN1 gene, while the remaining $5 \%$ of cases are caused by missense mutations, splice site mutations, or small deletions in SMN1 [53-58]. The phenotype of SMA is variable in both severity and age of onset, which can happen as early as before birth to as late as adulthood. Clinically, patients are classified into subgroups: SMA type I (severe), type II (intermediate), type III (mild) and type IV (adultonset) [59-61]. A summary of SMA modifiers is shown in Table 1.

SMN2. The wide-range of clinical presentation associated with SMA and the genetic homogeneity underlying the primary genetic defect in SMA strongly supports the presence of genetic modifiers. SMN2 is a gene highly homologous to $S M N 1$, arisen from gene duplication events of the SMN1 gene. Several independent studies have found $S M N 2$ copy number to be a strong predictor of SMA severity [62-66]. The single $\mathrm{C}>\mathrm{T}$ transition in $S M N 2$ exon 7 results in exclusion of this exon in $\sim 85 \%$ of SMN2 transcripts [67]. The SMN2 transcripts missing exon 7 produce a less stable protein [67] with reduced oligomerization capacity [68]. SMN2 deletion on its own has no phenotype in humans, and 5-14\% of normal individuals, with at least 
two copies of $S M N 1$, carry zero copies of $S M N 2$ [54, 62]. In patients with SMA however, SMN2 copy number is inversely correlated with disease severity; SMA patients with one or two copies of SMN2 have a more severe form of disease than patients carrying 3 or 4 copies of SMN2 [62]. This inverse dose response was affirmed in a mouse model of SMA, where a human SMN2 transgene at high copy number rescued the motor neuron deficit of these mice [69]. Several small molecules have been shown to increase SMN2 expression and ameliorate disease phenotypes in mouse models, patient cells lines, and human pilot studies [70-75].

PLS3. Comparison of whole transcriptomes of lymphoblastoid cell lines from affected versus unaffected siblings with the same SMN1/2 status identified PLS3 as a protective modifier of SMA [15]. PLS3 encodes Plastin 3, also known as T-Plastin, a protein involved in the formation and stabilization of actin bundles [76]. PLS3 is a sex-specific modifier; unaffected SMNdeleted females expressed higher levels of PLS3 in blood, whereas males overexpressing $P L S 3$ are not protected from SMA [15]. PLS3 is encoded on the $\mathrm{X}$ chromosome, and PLS3 expression in blood correlates inversely with disease severity, but only in post-pubertal female patients [77]. In a mouse model of SMA, PLS3 overexpression delays axonal pruning and rescues neuromuscular junction function by stabilizing F-actin dependent processes [78]. This modifying effect was also seen in zebrafish where overexpression of PLS3 was able to rescue neuromuscular defects in $S M N$ deficient fish $[15,79]$. The molecular basis of $P L S 3$ overexpression in unaffected individuals is unknown.

ZPR1. ZPR1 encodes Zinc Finger Protein 1 and was identified as a protective modifier of SMA in a candidate gene study investigating the expression of SMN interacting proteins in lymphoblastoid cell lines from SMA patients versus controls [80]. ZPR1 protein levels are elevated in lymphoblastoid cell lines from mildly affected SMA patients and controls compared to severely affected patients [80]. ZPR1 facilitates SMN accumulation in nuclear bodies, and the ZPR1-SMN interaction is disrupted in SMA patients [81]. In a mouse model of SMA, reduction in the level of ZPR1 results in increased disease severity and decreased lifespan [82]. In cell lines from SMA patients, overexpression of ZPR1 results in increased SMN protein levels, without a change in SMN mRNA expression, suggesting that ZPR1's interaction with SMN stabilizes the SMN protein complex and prevents turnover
[82]. As is the case with PLS3, the genetic basis of ZPR1 overexpression is unknown.

\section{MODIFIERS OF ALS}

Similar to SMA, amyotrophic lateral sclerosis (ALS) is marked by progressive degeneration of motor neurons and muscle weakness. The genetic causes of ALS are far more heterogeneous than SMA, and only in $10 \%$ of ALS cases is there a known genetic cause. Approximately $20 \%$ of familial ALS cases are caused by mutation in the $\mathrm{Cu} / \mathrm{Zn}$ superoxide dismutase 1 (SOD1) gene [83, 84]. Age of onset is typically later in life, on average around 50 years, and most patients die within 2-5 years of diagnosis. However, the clinical presentation of ALS is quite variable, both in age of onset and disease duration.

Mouse models. In a mouse model of ALS, mice that carry the same SOD1 mutation have considerable variation in disease severity depending on background strain $[85,86]$, indicating that genetic modifiers are playing a role. Transcriptomic analysis of mice from two of these strains revealed multiple potential modifier genes and pathways associated with slow or fast disease progression [87]. Candidate gene analysis has been widely tested by cross-breeding SOD1 mutant mice with genetically modified strains. These studies have identified many genes that, when perturbed, result in differences in disease onset or survival of these mice (reviewed in [2, 88]).

$S M N$. SMN, the gene responsible for SMA, has also been shown to modify ALS. A genomewide mapping screen for modifiers of the SOD1 mouse phenotype was conducted analyzing genetic loci for delayed onset of disease [86]. A strong linkage signal was found on chromosome 13, the locus containing Smn [86]. Follow up studies showed that cell lines expressing SOD1 mutant protein had less SMN protein expression than lines transfected with WT SOD1. Both SOD1 mutant mice and human patients with ALS have lower than normal levels of SMN in their spinal cords [2,3]. Additionally, SOD1 mutant mice with a genetic reduction of SMN display a more severe ALS phenotype [3], whereas neuronal overexpression of SMN ameliorates the ALS phenotype [2]. Taken together, these data indicate that SMN acts as a protective modifier in ALS, just as $\mathrm{SMN}$ is protective in SMA.

EPHA4. Ephrin type A receptor 4 (EPHA4) was identified as a modifier of ALS in a genetic screen in zebrafish overexpressing mutant SOD1. A morpholino-based 
genetic screen identified 13 genes that, when reduced, rescued the mutant phenotype. The most protective morpholino was directed against zebrafish gene Rtk2, which is $67 \%$ identical to human EPHA4 [1]. Pharmacological inhibition of Epha4 using 2,5dimethylpyrrolyl benzoic acid had the same rescue effect as the morpholino. EPHA4 is a receptor tyrosine kinase that interacts with ephrins-signaling molecules that are involved in axonal repulsion and regulation of synapse formation [89]. EPHA4 also acts as a modifier of ALS in mice, rats, and humans. In mice with SOD1 mutations, a 50\% genetic reduction of Epha4 increases motor performance and survival [1]. In SOD1-mutant rats, treatment with an EPHA4blocking peptide delayed disease onset and increased survival [1]. In humans, lower EPHA4 mRNA expression in blood from ALS patients is associated with later disease onset and prolonged survival. However, a genetic-association study of SNPs surrounding the EPHA4 locus did not find any associations between EPHA4 SNPs and ALS susceptibility, survival, or age at onset [1]. This negative result does not exclude EPH4A as a genetic modifier, since EPHA4 regulation may be regulated by trans-acting factors.

\section{CONCLUSIONS}

Neuromuscular disease has provided an excellent paradigm in which to demonstrate the role of genetic modifiers. The past decade has seen remarkable success in defining the complex genetic modifiers that influence neuromuscular disease outcome. For many of the modifier genes that have been identified, the precise genetic sequences that drive the modifier effect have not fully been explained. The observation that expression changes of many of these genes are sufficient to determine mild or severe disease is beneficial, and reveals essential information about new pathways involved in disease pathogenesis. Additional knowledge of the precise genetic changes that mediate these effects could augment genetic testing, prognosis, and treatment for individuals with different genetic makeup. As it stands now, those pathways by which expression levels can change the course of disease provide good drug targets.

\section{REFERENCES}

[1] Van Hoecke, A., Schoonaert, L., Lemmens, R., Timmers, M., Staats, K. A., Laird, A. S., Peeters, E., Philips, T., Goris, A., Dubois, B., Andersen, P. M., Al-Chalabi, A., Thijs, V., Turnley, A. M., van Vught, P. W., Veldink, J. H., Hardiman,
O., Van Den Bosch, L., Gonzalez-Perez, P., Van Damme, P., Brown, R. H., Jr., van den Berg, L. H., and Robberecht, W. EPHA4 is a disease modifier of amyotrophic lateral sclerosis in animal models and in humans. Nat Med. 2012; 18(9): 1418-1422.

[2] Turner, B. J., Alfazema, N., Sheean, R. K., Sleigh, J. N., Davies, K. E., Horne, M. K., and Talbot, K. Overexpression of survival motor neuron improves neuromuscular function and motor neuron survival in mutant SOD1 mice. Neurobiol Aging. 2014; 35(4): 906-915.

[3] Turner, B. J., Parkinson, N. J., Davies, K. E., and Talbot, K. Survival motor neuron deficiency enhances progression in an amyotrophic lateral sclerosis mouse model. Neurobiology of Disease. 2009; 34(3): 511-517.

[4] Kariya, S., Re, D. B., Jacquier, A., Nelson, K., Przedborski, S., and Monani, U. R. Mutant superoxide dismutase 1 (SOD1), a cause of amyotrophic lateral sclerosis, disrupts the recruitment of SMN, the spinal muscular atrophy protein to nuclear Cajal bodies. Hum Mol Genet. 2012; 21(15): 3421-3434.

[5] Eschbach, J., Schwalenstocker, B., Soyal, S. M., Bayer, H., Wiesner, D., Akimoto, C., Nilsson, A.-C., Birve, A., Meyer, T., Dupuis, L., Danzer, K. M., Andersen, P. M., Witting, A., Ludolph, A. C., Patsch, W., and Weydt, P. PGC-1alpha is a male-specific disease modifier of human and experimental amyotrophic lateral sclerosis. Human Molecular Genetics. 2013; 22(17): 3477-3484.

[6] Weydt, P., Soyal, S. M., Landwehrmeyer, G. B., and Patsch, W. A single nucleotide polymorphism in the coding region of PGC-1alpha is a male-specific modifier of Huntington disease age-at-onset in a large European cohort. BMC Neurol. 2014; 14: 1 .

[7] Emery, A. E. Population frequencies of inherited neuromuscular diseases-a world survey. Neuromuscul Disord. 1991; 1(1): 19-29.

[8] Larkindale, J., Yang, W., Hogan, P. F., Simon, C. J., Zhang, Y., Jain, A., Habeeb-Louks, E. M., Kennedy, A., and Cwik, V. A. Cost of illness for neuromuscular diseases in the United States. Muscle \& Nerve. 2014; 49(3): 431-438.

[9] Bello, L., Piva, L., Barp, A., Taglia, A., Picillo, E., Vasco, G., Pane, M., Previtali, S. C., Torrente, Y., Gazzerro, E., Motta, M. C., Grieco, G. S., Napolitano, S., Magri, F., D’Amico, A., Astrea, G., Messina, S., Sframeli, M., Vita, G. L., Boffi, P., Mongini, T., Ferlini, A., Gualandi, F., Soraru, G., Ermani, M., Vita, G., Battini, R., Bertini, E., Comi, G. P., Berardinelli, A., Minetti, C., Bruno, C., Mercuri, E., Politano, L., Angelini, C., Hoffman, E. P., and Pegoraro, E. Importance of SPP1 genotype as a covariate in clinical trials in Duchenne muscular dystrophy. Neurology. 2012; 79(2): 159-162.

[10] Sleigh, J. N., Barreiro-Iglesias, A., Oliver, P. L., Biba, A., Becker, T., Davies, K. E., Becker, C. G., and Talbot, K. Chondrolectin affects cell survival and neuronal outgrowth in in vitro and in vivo models of spinal muscular atrophy. Hum Mol Genet. 2014; 23(4): 855-869.

[11] Giess, R., Holtmann, B., Braga, M., Grimm, T., MullerMyhsok, B., Toyka, K. V., and Sendtner, M. Early onset of severe familial amyotrophic lateral sclerosis with a SOD-1 mutation: Potential impact of CNTF as a candidate modifier gene. Am J Hum Genet. 2002; 70(5): 1277-1286.

[12] Pegoraro, E., Hoffman, E. P., Piva, L., Gavassini, B. F., Cagnin, S., Ermani, M., Bello, L., Soraru, G., Pacchioni, B., Bonifati, M. D., Lanfranchi, G., Angelini, C., Kesari, A., Lee, I., Gordish-Dressman, H., Devaney, J. M., and McDonald, C. M. SPP1 genotype is a determinant of disease severity in Duchenne muscular dystrophy. Neurology. 2011; 76(3): 219-226. 
[13] Chang, H. C., Dimlich, D. N., Yokokura, T., Mukherjee, A., Kankel, M. W., Sen, A., Sridhar, V., Fulga, T. A., Hart, A. C., Van Vactor, D., and Artavanis-Tsakonas, S. Modeling spinal muscular atrophy in Drosophila. PLoS One. 2008; 3(9): e3209.

[14] Dimitriadi, M., Sleigh, J. N., Walker, A., Chang, H. C., Sen, A., Kalloo, G., Harris, J., Barsby, T., Walsh, M. B., Satterlee, J. S., Li, C., Van Vactor, D., Artavanis-Tsakonas, S., and Hart, A. C. Conserved genes act as modifiers of invertebrate SMN loss of function defects. PLoS Genet. 2010; 6(10): e1001172.

[15] Oprea, G. E., Krober, S., McWhorter, M. L., Rossoll, W., Muller, S., Krawczak, M., Bassell, G. J., Beattie, C. E., and Wirth, B. Plastin 3 is a protective modifier of autosomal recessive spinal muscular atrophy. Science. 2008; 320(5875): 524-527.

[16] Granger, B., Gueneau, L., Drouin-Garraud, V., Pedergnana, V., Gagnon, F., Ben Yaou, R., Tezenas du Montcel, S., and Bonne, G. Modifier locus of the skeletal muscle involvement in Emery-Dreifuss muscular dystrophy. Hum Genet. 2011; 129(2): 149-159.

[17] Esteller, M. Non-coding RNAs in human disease. Nat Rev Genet. 2011; 12(12): 861-874.

[18] Berardi, E., Annibali, D., Cassano, M., Crippa, S., and Sampaolesi, M. Molecular and cell-based therapies for muscle degenerations: A road under construction. Front Physiol. 2014; 5:119.

[19] Kucherenko, M. M., Pantoja, M., Yatsenko, A. S., Shcherbata, H. R., Fischer, K. A., Maksymiv, D. V., Chernyk, Y. I., and Ruohola-Baker, H. Genetic modifier screens reveal new components that interact with the Drosophila dystroglycandystrophin complex. PLoS One. 2008; 3(6): e2418.

[20] Li, D. K., Tisdale, S., Espinoza-Derout, J., Saieva, L., Lotti, F., and Pellizzoni, L. A cell system for phenotypic screening of modifiers of SMN2 gene expression and function. PLoS One. 2013; 8(8): e71965.

[21] Vetrone, S. A., Montecino-Rodriguez, E., Kudryashova, E., Kramerova, I., Hoffman, E. P., Liu, S. D., Miceli, M. C., and Spencer, M. J. Osteopontin promotes fibrosis in dystrophic mouse muscle by modulating immune cell subsets and intramuscular TGF-beta. J Clin Invest. 2009; 119(6): 1583-1594.

[22] Turk, R., Sterrenburg, E., van der Wees, C. G., de Meijer, E. J., de Menezes, R. X., Groh, S., Campbell, K. P., Noguchi, S., van Ommen, G. J., den Dunnen, J. T., and t Hoen P. A. Common pathological mechanisms in mouse models for muscular dystrophies. FASEB J. 2006; 20(1): 127-129.

[23] Giacopelli, F., Marciano, R., Pistorio, A., Catarsi, P., Canini, S., Karsenty, G., and Ravazzolo, R. Polymorphisms in the osteopontin promoter affect its transcriptional activity. Physiol Genomics. 2004; 20(1): 87-96.

[24] Piva, L., Gavassini, B. F., Bello, L., Fanin, M., Soraru, G., Barp, A., Ermani, M., Angelini, C., Hoffman, E. P., and Pegoraro, E. TGFBR2 but not SPP1 genotype modulates osteopontin expression in Duchenne muscular dystrophy muscle. J Pathol. 2012; 228(2): 251-259.

[25] Craig, A. M., and Denhardt, D. T. The murine gene encoding secreted phosphoprotein 1 (osteopontin): Promoter structure, activity, and induction in vivo by estrogen and progesterone. Gene. 1991; 100: 163-171.

[26] Arjomandi, M., Galanter, J. M., Choudhry, S., Eng, C., Hu, D., Beckman, K., Chapela, R., Rodriguez-Santana, J. R., Rodriguez-Cintron, W., Ford, J., Avila, P. C., and Burchard, E. G. Polymorphism in osteopontin gene (SPP1) is associated with asthma and related phenotypes in a puerto rican population. Pediatr Allergy Immunol Pulmonol. 2011; 24(4): 207-214.
[27] Forton, A. C., Petri, M. A., Goldman, D., and Sullivan, K. E. An osteopontin (SPP1) polymorphism is associated with systemic lupus erythematosus. Hum Mutat. 2002; 19(4): 459.

[28] Gazal, S., Sacre, K., Allanore, Y., Teruel, M., Goodall, A. H., Tohma, S., Alfredsson, L., Okada, Y., Xie, G., Constantin, A., Balsa, A., Kawasaki, A., Nicaise, P., Amos, C., RodriguezRodriguez, L., Chioccia, G., Boileau, C., Zhang, J., Vittecoq, O., Barnetche, T., Gonzalez Gay, M. A., Furukawa, H., Cantagrel, A., Le Loet, X., Sumida, T., Hurtado-Nedelec, M., Richez, C., Chollet-Martin, S., Schaeverbeke, T., Combe, B., Khoryati, L., Coustet, B., El-Benna, J., Siminovitch, K., Plenge, R., Padyukov, L., Martin, J., Tsuchiya, N., and Dieude, P. Identification of secreted phosphoprotein 1 gene as a new rheumatoid arthritis susceptibility gene. Ann Rheum Dis. 2014, in press.

[29] Hendig, D., Arndt, M., Szliska, C., Kleesiek, K., and Gotting, C. SPP1 promoter polymorphisms: Identification of the first modifier gene for pseudoxanthoma elasticum. Clin Chem. 2007; 53(5): 829-836.

[30] Marciano, R., D’Annunzio, G., Minuto, N., Pasquali, L., Santamaria, A., Di Duca, M., Ravazzolo, R., and Lorini, R. Association of alleles at polymorphic sites in the Osteopontin encoding gene in young type 1 diabetic patients. Clin Immunol. 2009; 131(1): 84-91.

[31] Niino, M., Kikuchi, S., Fukazawa, T., Yabe, I., and Tashiro, $\mathrm{K}$. Genetic polymorphisms of osteopontin in association with multiple sclerosis in Japanese patients. J Neuroimmunol. 2003; 136(1-2): 125-129.

[32] Uaesoontrachoon, K., Yoo, H. J., Tudor, E. M., Pike, R. N., Mackie, E. J., and Pagel, C. N. Osteopontin and skeletal muscle myoblasts: Association with muscle regeneration and regulation of myoblast function in vitro. Int J Biochem Cell Biol. 2008; 40(10): 2303-2314.

[33] Hoffman, E. P., Gordish-Dressman, H., McLane, V. D., Devaney, J. M., Thompson, P. D., Visich, P., Gordon, P. M., Pescatello, L. S., Zoeller, R. F,. Moyna, N. M., Angelopoulos, T. J., Pegoraro, E., Cox, G. A., and Clarkson, P. M. Alterations in osteopontin modify muscle size in females in both humans and mice. Med Sci Sports Exerc. 2013; 45(6): 1060-1068.

[34] Hullinger, T. G., Pan, Q., Viswanathan, H. L., and Somerman, M. J. TGFbeta and BMP-2 activation of the OPN promoter: Roles of smad- and hox-binding elements. Exp Cell Res. 2001; 262(1): 69-74.

[35] Han, S., Guthridge, J. M., Harley, I. T., Sestak, A. L., KimHoward, X., Kaufman, K. M., Namjou, B., Deshmukh, H., Bruner, G., Espinoza, L. R., Gilkeson, G. S., Harley, J. B., James, J. A., and Nath, S. K. Osteopontin and systemic lupus erythematosus association: A probable gene-gender interaction. PLoS One. 2008; 3(3): e0001757.

[36] Heydemann, A., Ceco, E., Lim, J. E., Hadhazy, M., Ryder, P., Moran, J. L., Beier, D. R., Palmer, A. A., and McNally, E. M. Latent TGF-beta-binding protein 4 modifies muscular dystrophy in mice. J Clin Invest. 2009; 119(12): 3703-3712.

[37] Heydemann, A., Huber, J. M., Demonbreun, A., Hadhazy, M., and McNally, E. M. Genetic background influences muscular dystrophy. Neuromuscul Disord. 2005; 15(9-10): 601-609.

[38] Straub, V., Rafael, J. A., Chamberlain, J. S., and Campbell, K. P. Animal models for muscular dystrophy show different patterns of sarcolemmal disruption. J Cell Biol. 1997; 139(2): 375-385.

[39] Flanigan, K. M., Ceco, E., Lamar, K. M., Kaminoh, Y., Dunn, D. M., Mendell, J. R., King, W. M., Pestronk, A., Florence, J. M., Mathews, K. D., Finkel, R. S., Swoboda, K. J., Gappmaier, E., Howard, M. T., Day, J. W., McDonald, C., McNally, E. M., and Weiss, R. B. LTBP4 genotype predicts age of ambulatory 
loss in duchenne muscular dystrophy. Ann Neurol. 2013; 73(4): 481-488.

[40] Bernasconi, P., Di Blasi, C., Mora, M., Morandi, L., Galbiati, S., Confalonieri, P., Cornelio, F., and Mantegazza, R. Transforming growth factor-betal and fibrosis in congenital muscular dystrophies. Neuromuscul Disord. 1999; 9(1): 28-33.

[41] Onofre-Oliveira, P. C., Santos, A. L., Martins, P. M., AyubGuerrieri, D., and Vainzof, M. Differential expression of genes involved in the degeneration and regeneration pathways in mouse models for muscular dystrophies. Neuromolecular Med. 2012; 14(1): 74-83.

[42] Branton, M. H., and Kopp, J. B. TGF-beta and fibrosis. Microbes Infect. 1999; 1(15): 1349-1365

[43] Hersh, C. P., Demeo, D. L., Lazarus, R., Celedon, J. C., Raby, B. A., Benditt, J. O., Criner, G., Make, B., Martinez, F. J., Scanlon, P. D., Sciurba, F. C., Utz, J. P., Reilly, J. J., and Silverman, E. K. Genetic association analysis of functional impairment in chronic obstructive pulmonary disease. Am J Respir Crit Care Med. 2006; 173(9): 977-984.

[44] Forsti, A., Li, X., Wagner, K., Tavelin, B., Enquist, K., Palmqvist, R., Altieri, A., Hallmans, G., Hemminki, K., and Lenner, P. Polymorphisms in the transforming growth factor beta 1 pathway in relation to colorectal cancer progression. Genes Chromosomes Cancer. 2010; 49(3): 270-281

[45] Thompson, A. R., Cooper, J. A., Jones, G. T., Drenos, F., van Bockxmeer, F. M., Biros, E., Walker, P. J., van Rij, A. M., Golledge, J., Norman, P. E., Hafez, H., and Humphries, S. E. Assessment of the association between genetic polymorphisms in transforming growth factor beta, and its binding protein (LTBP), and the presence, and expansion, of Abdominal Aortic Aneurysm. Atherosclerosis. 2010; 209(2): 367-373

[46] Swaggart, K. A., Demonbreun, A. R., Vo, A. H., Swanson, K. E., Kim, E. Y., Fahrenbach, J. P., Holley-Cuthrell, J., Eskin, A., Chen, Z., Squire, K., Heydemann, A., Palmer, A. A., Nelson, S. F., and McNally, E. M. Annexin A6 modifies muscular dystrophy by mediating sarcolemmal repair. Proc Natl Acad Sci U S A. 2014; 111(16): 6004-6009.

[47] Camors, E., Monceau, V., and Charlemagne, D. Annexins and $\mathrm{Ca} 2+$ handling in the heart. Cardiovasc Res. 2005; 65(4): 793-802.

[48] Lennon, N. J., Kho, A., Bacskai, B. J., Perlmutter, S. L., Hyman, B. T., and Brown, R. H., Jr. Dysferlin interacts with annexins $\mathrm{A} 1$ and $\mathrm{A} 2$ and mediates sarcolemmal woundhealing. J Biol Chem. 2003; 278(50): 50466-50473.

[49] Cagliani, R., Magri, F., Toscano, A., Merlini, L., Fortunato, F., Lamperti, C., Rodolico, C., Prelle, A., Sironi, M., Aguennouz, M., Ciscato, P., Uncini, A., Moggio, M., Bresolin, N., and Comi, G. P. Mutation finding in patients with dysferlin deficiency and role of the dysferlin interacting proteins annexin A1 and A2 in muscular dystrophies. Hum Mutat. 2005; 26(3): 283.

[50] Babiychuk, E. B., and Draeger, A. Annexins in Cell Membrane Dynamics: Ca2+-Regulated Association of Lipid Microdomains. The Journal of Cell Biology. 2000; 150(5): 1113-1124.

[51] Draeger, A., Monastyrskaya, K., Burkhard, F. C., Wobus, A. M., Moss, S. E., and Babiychuk, E. B. Membrane segregation and downregulation of raft markers during sarcolemmal differentiation in skeletal muscle cells. Developmental Biology. 2003; 262(2): 324-334.

[52] Roostalu, U., and Strahle, U. In vivo imaging of molecular interactions at damaged sarcolemma. Dev Cell. 2012; 22(3): 515-529.
[53] He, J., Zhang, Q. J., Lin, Q. F., Chen, Y. F., Lin, X. Z., Lin, M. T., Murong, S. X., Wang, N., and Chen, W. J. Molecular analysis of SMN1, SMN2, NAIP, GTF2H2, and H4F5 genes in 157 Chinese patients with spinal muscular atrophy. Gene. 2013; 518(2): 325-329.

[54] Lefebvre, S., Burglen, L., Reboullet, S., Clermont, O., Burlet, P., Viollet, L., Benichou, B., Cruaud, C., Millasseau, P., Zeviani, M., et al. Identification and characterization of a spinal muscular atrophy-determining gene. Cell. 1995; 80(1): 155-165.

[55] Cobben, J. M., van der Steege, G., Grootscholten, P., de Visser, M., Scheffer, H., Buys, C. H. Deletions of the survival motor neuron gene in unaffected siblings of patients with spinal muscular atrophy. Am J Hum Genet. 1995; 57(4): 805-808.

[56] Hahnen, E., Forkert, R., Marke, C., Rudnik-Schoneborn, S., Schonling, J., Zerres, K., and Wirth, B. Molecular analysis of candidate genes on chromosome 5q13 in autosomal recessive spinal muscular atrophy: Evidence of homozygous deletions of the SMN gene in unaffected individuals. Hum Mol Genet. 1995; 4(10): 1927-1933.

[57] Bussaglia, E., Clermont, O., Tizzano, E., Lefebvre, S., Burglen, L., Cruaud, C., Urtizberea, J. A., Colomer, J., Munnich, A., Baiget, M., et al. A frame-shift deletion in the survival motor neuron gene in Spanish spinal muscular atrophy patients. Nat Genet. 1995; 11(3): 335-337.

[58] Brahe, C., Clermont, O., Zappata, S., Tiziano, F., Melki, J., and Neri, G. Frameshift mutation in the survival motor neuron gene in a severe case of SMA type I. Hum Mol Genet. 1996; 5(12): 1971-1976.

[59] Dubowitz, V. Chaos in classification of the spinal muscular atrophies of childhood. Neuromuscular Disorders. 1991; 1(2): 77-80.

[60] Dubowitz, V. Chaos in the classification of SMA: A possible resolution. Neuromuscular Disorders. 1995; 5(1): 3-5.

[61] Russman, B. S. Spinal muscular atrophy: Clinical classification and disease heterogeneity. J Child Neurol. 2007; 22(8): 946-951.

[62] Mailman, M. D., Heinz, J. W., Papp, A. C., Snyder, P. J., Sedra, M. S., Wirth, B., Burghes, A. H., and Prior, T. W. Molecular analysis of spinal muscular atrophy and modification of the phenotype by SMN2. Genet Med. 2002; 4(1): 20-26.

[63] Burghes, A. H. M. When is a deletion not a deletion? When it is converted. The American Journal of Human Genetics. 1997; 61(1): 9-15.

[64] Feldkotter, M., Schwarzer, V., Wirth, R., Wienker, T. F., and Wirth, B. Quantitative analyses of SMN1 and SMN2 based on real-time lightCycler PCR: Fast and highly reliable carrier testing and prediction of severity of spinal muscular atrophy. Am J Hum Genet. 2002; 70(2): 358-368.

[65] Harada, Y., Sutomo, R., Sadewa, A. H., Akutsu, T., Takeshima, Y., Wada, H., Matsuo, M., and Nishio, H. Correlation between SMN2 copy number and clinical phenotype of spinal muscular atrophy: Three SMN2 copies fail to rescue some patients from the disease severity. J Neurol. 2002; 249(9): 1211-1219.

[66] Wirth, B., Brichta, L., Schrank, B., Lochmuller, H., Blick, S., Baasner, A., Heller, R. Mildly affected patients with spinal muscular atrophy are partially protected by an increased SMN2 copy number. Hum Genet. 2006; 119(4): 422-428.

[67] Lorson, C. L., and Androphy, E. J. An exonic enhancer is required for inclusion of an essential exon in the SMAdetermining gene SMN. Hum Mol Genet. 2000; 9(2): 259-265.

[68] Lorson, C. L., Strasswimmer, J., Yao, J. M., Baleja, J. D., Hahnen, E., Wirth, B., Le, T., Burghes, A. H., and Androphy, E. J. 
SMN oligomerization defect correlates with spinal muscular atrophy severity. Nat Genet. 1998; 19(1): 63-66.

[69] Monani, U. R., Sendtner, M., Coovert, D. D., Parsons, D. W., Andreassi, C., Le, T. T., Jablonka, S., Schrank, B., Rossoll, W., Prior, T. W., Morris, G. E., and Burghes, A. H. The human centromeric survival motor neuron gene (SMN2) rescues embryonic lethality in Smn(-/-) mice and results in a mouse with spinal muscular atrophy. Hum Mol Genet. 2000; 9(3): 333-339.

[70] Andreassi, C., Angelozzi, C., Tiziano, F. D., Vitali, T., De Vincenzi, E., Boninsegna, A., Villanova, M., Bertini, E., Pini, A., Neri, G., and Brahe, C. Phenylbutyrate increases SMN expression in vitro: Relevance for treatment of spinal muscular atrophy. Eur J Hum Genet. 2004; 12(1): 59-65.

[71] Brahe, C., Vitali, T., Tiziano, F. D., Angelozzi, C., Pinto, A. M., Borgo, F., Moscato, U., Bertini, E., Mercuri, E., and Neri, G. Phenylbutyrate increases SMN gene expression in spinal muscular atrophy patients. Eur J Hum Genet. 2005; 13(2): 256-259.

[72] Mercuri, E., Bertini, E., Messina, S., Pelliccioni, M., D'Amico, A., Colitto, F., Mirabella, M., Tiziano, F. D., Vitali, T., Angelozzi, C., Kinali, M., Main, M., and Brahe, C. Pilot trial of phenylbutyrate in spinal muscular atrophy. Neuromuscul Disord. 2004; 14(2): 130-135.

[73] Brichta, L., Holker, I., Haug, K., Klockgether, T., and Wirth, B. In vivo activation of SMN in spinal muscular atrophy carriers and patients treated with valproate. Ann Neurol. 2006; 59(6): 970-975.

[74] Swoboda, K. J., Scott, C. B., Reyna, S. P., Prior, T. W., LaSalle, B., Sorenson, S. L., Wood, J., Acsadi, G., Crawford, T. O., Kissel, J. T., Krosschell, K. J., D’Anjou, G., Bromberg, M. B., Schroth, M. K., Chan, G. M., Elsheikh, B., and Simard, L. R. Phase II open label study of valproic acid in spinal muscular atrophy. PLoS One. 2009; 4(5): e5268.

[75] Riessland, M., Ackermann, B., Forster, A., Jakubik, M., Hauke, J., Garbes, L., Fritzsche, I., Mende, Y., Blumcke, I., Hahnen, E., and Wirth, B. SAHA ameliorates the SMA phenotype in two mouse models for spinal muscular atrophy. Human Molecular Genetics. 2010; 19(8): 1492-1506.

[76] Giganti, A., Plastino, J., Janji, B., Van Troys, M., Lentz, D., Ampe, C., Sykes, C., Friederich, E. Actin-filament cross-linking protein T-plastin increases Arp2/3-mediated actin-based movement. J Cell Sci. 2005; 118(Pt 6): 12551265.

[77] Stratigopoulos, G., Lanzano, P., Deng, L., et al. ASsociation of plastin 3 expression with disease severity in spinal muscular atrophy only in postpubertal females. Archives of Neurology. 2010; 67(10): 1252-1256

[78] Ackermann, B., Krober, S., Torres-Benito, L., Borgmann, A., Peters, M., Hosseini Barkooie, S. M., Tejero, R., Jakubik, M., Schreml, J., Milbradt, J., Wunderlich, T. F., Riessland,
M., Tabares, L., and Wirth, B. Plastin 3 ameliorates spinal muscular atrophy via delayed axon pruning and improves neuromuscular junction functionality. Hum Mol Genet. 2013; 22(7): 1328-1347.

[79] Hao le, T., Wolman, M., Granato, M., and Beattie, C. E. Survival motor neuron affects plastin 3 protein levels leading to motor defects. J Neurosci. 2012; 32(15): 5074-5084.

[80] Helmken, C., Hofmann, Y., Schoenen, F., Oprea, G., Raschke, H., Rudnik-Schoneborn, S., Zerres, K., and Wirth, B. Evidence for a modifying pathway in SMA discordant families: Reduced SMN level decreases the amount of its interacting partners and Htra2-beta1. Human Genetics. 2003; 114(1): 11-21.

[81] Gangwani, L., Mikrut, M., Theroux, S., Sharma, M., and Davis, R. J. Spinal muscular atrophy disrupts the interaction of ZPR1 with the SMN protein. Nat Cell Biol. 2001; 3(4): 376-383.

[82] Ahmad, S., Wang, Y., Shaik, G. M., Burghes, A. H., and Gangwani, L. The zinc finger protein ZPR1 is a potential modifier of spinal muscular atrophy. Hum Mol Genet. 2012; 21(12): 2745-2758.

[83] Rosen, D. R., Sapp, P., O'Regan, J., McKenna-Yasek, D., Schlumpf, K. S., Haines, J. L., Gusella, J. F., Horvitz, H. R., and Brown, R. H., Jr. Genetic linkage analysis of familial amyotrophic lateral sclerosis using human chromosome 21 microsatellite DNA markers. Am J Med Genet. 1994; 51(1): 61-69.

[84] Deng, H. X., Hentati, A., Tainer, J. A., Iqbal, Z., Cayabyab, A., Hung, W. Y., Getzoff, E. D., Hu, P., Herzfeldt, B., Roos, R. P., et al. Amyotrophic lateral sclerosis and structural defects in $\mathrm{Cu}, \mathrm{Zn}$ superoxide dismutase. Science. 1993; 261(5124): 1047-1051.

[85] Mancuso, R., Olivan, S., Mancera, P., Pasten-Zamorano, A., Manzano, R., Casas, C., Osta, R., and Navarro, X. Effect of genetic background on onset and disease progression in the SOD1-G93A model of amyotrophic lateral sclerosis. Amyotroph Lateral Scler. 2012; 13(3): 302-310.

[86] Kunst, C. B., Messer, L., Gordon, J., Haines, J., and Patterson, D. Genetic mapping of a mouse modifier gene that can prevent ALS onset. Genomics. 2000; 70(2): 181-189.

[87] Nardo, G., Iennaco, R., Fusi, N., Heath, P. R., Marino, M., Trolese, M. C., Ferraiuolo, L., Lawrence, N., Shaw, P. J., and Bendotti, C. Transcriptomic indices of fast and slow disease progression in two mouse models of amyotrophic lateral sclerosis. Brain. 2013; 136(Pt 11): 3305-3332.

[88] Riboldi, G., Nizzardo, M., Simone, C., Falcone, M., Bresolin, N., Comi, G. P., and Corti, S. ALS genetic modifiers that increase survival of SOD1 mice and are suitable for therapeutic development. Prog Neurobiol. 2011; 95(2): 133-148.

[89] Klein, R. Bidirectional modulation of synaptic functions by Eph/ephrin signaling. Nat Neurosci. 2009; 12(1): 15-20. 